\title{
Ueber das Tellurmethyl;
}

\section{von F. Wöhler und J. Dean.}

Dafs es eine Verbindung des Tellurs mit dem Radical des Methylalkohols geben müsse, war nicht schwer vorauszusehen, nachdem einmal die entsprechende Aethylverbindung bekannt war. Auch nehmen wir für die kleine Arbeit, die wir in dem Folgenden mittheilen wollen, nur das Verdienst in Anspruch, uns den Widerwärtigkeiten unterzogen zu haben, die mit der Untersuchung eines so höchst übel riechenden Körpers unvermeidlich verbunden sind.

Die Darstellung des Tellurmethyls geschah auf ganz ähnliche Weise wie die des Telluräthyls *), nämlich durch Destillation von Tellurkalium mit einer ziemlich concentrirten Lösung von methyloxydschwefelsaurem Baryt. Die Bildung geht sehr leicht vor sich. Die Destillation wurde so lange fortgesetzt, als mit dem Wasser noch Oeltropfen übergingen.

Das Tellurmethyl ist ein blafsgelbes, leicht bewegliches, in Wasser untersinkendes, damit nicht mischbares Liquidum. Sein Geruch ist höchst unangenehm, knoblauchähnlich, sehr intensiv und so lange haftend, dafs selbst der Athem bei der Beschäftigung damit auf einige Zeit den Geruch annimmt. Seinen Siedepunkt fanden wir bei $82^{\circ} \mathrm{C} .{ }^{* *}$ ). Sein Gas ist gelb, wie das des Tellurs selbst. An der Luft raucht es

*) Diese Annalen LXXXIV, 79.

*) Sehr wahrscheinlich ist der Siedepunkt schon bei $80^{\circ}$, denn bei dem Versuch war das Tellurmethyl mit einer kleinen Wasserschicht bedeckt, und das Thermometer tauchte nicht unmittelbar in dasselbe, sondern in $\mathrm{Oel}$, in welches die übrigens sehr dünne Röhre mit dem Tellurmethyl gesenkt war.

Nimnit man $80^{\circ}$ als den richtigen Siedepunkt an, so mufs, nach dem Geseiz von H. Kopp, der Siedepunkt des Telluräthyls, der noch nicht durch den Versuch bestiunt ist, bei $99^{\circ}$ seyn. 
schwach in Folge einer 0xydation. Angezündet verbrennt es mit hell leuchtender, bläulich weifser Flamme, unter Verbreitung eines dicken Rauchs von telluriger Säure.

Das Tellurmethyl, $\mathrm{C}^{2} \mathrm{H}^{3} \mathrm{Te}$, verhält sich, gleich dem Telluräthyl, wie ein Radical, wie ein Metall. Es bildet ein basisches Oxyd und die diesem correspondirenden Haloïd-Verbindungen. Seine unmittelbare Analyse hielten wir für überflüssig, da seine Zusammensetzung aus der seiner Verbindungen, die Jeichter zu analysiren sind, mit Sicherheit geschlossen werden konnte.

Tellurmethyloxyd, $\mathrm{C}^{2} \Psi^{3}$ Te0. Es enlsteht, wenn Tellurmethyl mit märsig starker Salpetersäure erwärmt wird. Zuerst löst sich ein Theil mit rothgelber Farbe auf, dann tritt plötzlich, unter Entwickelung von Stickoxydgas, eine heftige Reaction ein und man hat eine farblose Lösung von salpetersaurem Tellurmethyloxyd. Nach dem vorsichtigen Verdunsten erhält man das Salz in grofsen, farblosen Prismen krystallisirt *). Es ist sowohl in Wasser als in Alkohol leicht löslich. Beim Erhitzen zersetzt es sich unter Verpuffung. Es ist das Material zur Darstellung aller anderen Verbindungen. Indessen fauden wir es am einfachsten, das Tellurmethyloxyd nicht aus diesem Salz, sondern aus der Chlor- oder JodVerbindung des Tellurmethyls durch Zersetzung mit Silberoxyd darzustellen. Die Verbindung wurde mit etwas Wasser übergossen und Silberoxyd, durch Barytwasser frisch gefällt und wohl ausgewaschen, im Ueberschufs beigemischt. Die Zersetzung beginnt augenblicklich und unter freiwilliger Erwär-

*) Zuweilen, wahrscheinlich bei zu viel und zu starker Săure, erhielten wir das Salz beiın Verdunsten nicht krystallisirbar, sondern als klare, amorphe Masse. In diesem Falle enthält es, wie es scheint in Folge der Zerstörung eines Theils des Methyls, tellurige Săure beigemengt oder in Verbindung. 
mung der Masse. In der von dem Chlor-oder Jodsilber abfiltrirten Flüssigkeit hat man die Base aufgelöst.

Das Tellurmethyloxyd ist in trockenem Zustand undeutlich krystallinisch. An der Luft zerfliefst es, wie Kali, indem es zugleich Kohlensäure anzieht. Es hat einen abscheulichen Geschmack, ist aber geruchlos. Seine Lösung reagirt auf rothes Lackmuspapier stark alkalisch. Es ist ein so starkes Alkali, dafs es schon bei gewöhnlicher Temperatur aus Salmiak Ammoniak entwickelt und in schwefelsaurem Kupferoxyd einen blauen Niederschlag bildet. Aus seiner Lösung reducirt schweflige Säure sogleich ölförmiges, stinkendes Tellurmethyl; Salzsäure fällt daraus weifses Chlorür, Jodwasserstoffsäure rothes Jodür.

Das schwefelsaure Tellurmethyloxyd, gebildet durch unmittelbare Sättigung der Base mit der Säure, krystallisirt in klaren, ansehnlich grofsen, sehr regelmäfsigen Würfeln. In Wasser ist es leicht löslich, in Alkohol unlöslich.

Andere Salze konnten wir aus Mangel an Material nicht darstellen. Wir überzeugten uns nur, dafs die Salze von Oxalsäure, Weinsäure, Essigsäure und Ameisensäure leicht löslich sind.

Tellurmethyl-Chlorür, $\mathrm{C}^{2} \mathrm{H}^{\mathbf{3}} \mathrm{TeGl}$. Es entsteht als dicker, weifser, dem Chlorblei ähnlicher Niederschlag, wenn man Chlorwasserstoffsäure in die Lösung des salpetersauren Salzes tropft. Beim Erwärmen löst es sich wieder auf und krystallisirt dann beim Erkalten in langen, dünnen Prismen, ähnlich dem Quecksilberchlorid. Es schmilzt bei $\mathbf{9 7}^{\circ}, 5 \mathrm{C}$, scheint sich aber nicht ganz unzersetzt verflichligen zu lassen. Obgleich es sich nicht mit Wasser überdestilliren liefs, so besitzt doch seine erwärmte Lösung einen schwachen knoblauchähnlichen Geruch. Es erstarrt sehr krystallinisch. In Alkohol ist es leicht löslich. Wird es aus dem amorphen 
salpetersauren Salz bereitet, so enthält es tellurige Säure beigemengt oder in Verbindung. Mit Platinchlorid bildet es keinen Niederschlag.

Tellurmethyl-Oxychlorïr, $\mathrm{C}^{2} \mathrm{H}^{3} \mathrm{TeEl}+\mathrm{C}^{2} \mathrm{H}^{3} \mathrm{TeO}$, bildet sich bei der Auflösung des Chlorürs in Ammoniak. Nach dem Verdunsten erhält man ein Gemenge von Salmiak und Oxychlorür, die sich durch Alkohol leicht trennen lassen. Es bildet farblose, kurze Prismen. Salzsäure fällt aus seiner Lösung das Chlorür.

Tellurmethyl-Bromür, $\mathrm{C}^{2} \mathrm{H}^{3} \mathrm{TeBr}$. Es entsteht auf ganz ähnliche Weise wie das Chlorür, dem es überhaupt sehr ähnlich und womit es wahrscheinlich auch isomorph ist. Es bildet glänzende farblose Prismen und schmilzt bei $89^{\circ} \mathrm{C}$.

Tellurmethyl-Jodir, $\mathrm{C}^{2} \mathrm{H}^{3} \mathrm{Te}$. Tropft man in die Lösung des salpetersauren Tellurmethyloxyds oder des Tellurmethylchlorürs farblose Jodwasserstoffsäure oder eine Lösung von Jodkalium, so entsteht ein lebhaft citrongelber Niederschlag, der aber nach wenigen Augenblicken zinnoberroth wird. Vermischt man die Lösungen warm, so wird er unmittelbar roth und krystallinisch. Nach dem Trocknen bildet er ein zinnoberrothes Krystallpulver.

Dieses Jodür wurde zur Feststellung der Zusammenstellung des Tellurmethyls gewählt. Kohlenstoff und Wasserstoff wurden durch Verbrennung mit Kupferoxyd bestimmt, der Jodgehalt durch Fällung mit salpetersaurem Silberoxyd, der Tellurgehalt durch Zerstörung der Verbindung mit Königswasser, Eindampfen bis fast zur Trockne und Fällung des Tellurs mit schwefligsaurem Ammoniak.

$0,265 \mathrm{Grm}$. gaben $0,0525 \mathrm{CO}^{2}$ und $0,0386 \mathrm{HO}$.

$0,2665 \mathrm{Grm}$. gaben 0,305 Jodsilber.

$.0,2721$ Grm. gaben 0,085 Tellur; oder in 100 Theilen : 


\begin{tabular}{lcc} 
& Gefunden & $\begin{array}{c}\text { Nach der Formel } \\
\text { C'H }^{2} \mathbf{3}^{3} \text { Tef }\end{array}$ \\
Kohlenstofl & 5,40 & 5,81 \\
Wasserstoff & 1,61 & 1,45 \\
Tellur & 31,24 & 31,12 \\
Jod & 61,54 & 61,62 \\
\cline { 2 - 3 } & 99,79 & $100,00$.
\end{tabular}

In kaltem Wasser ist das Tellurmethyljodür nur wenig löslich, viel mehr in warmem. In reichlicher Menge und mit röthlich gelber Farbe ist es löslich in heifsem Alkohol. Aus beiden krystallisirt es beim Erkalten in kleinen, glänzenden, zinnoberrothen Prismen, die aus der Alkohollösung am grölsten werden. Sie geben ein orangegelbes Pulver. Unter dem Mikroscop erscheinen sie mit orangegelber Farbe durchsichtig und gewisse Flächen zeigen eine schöne blaue Oberflächenfarbe *).

Wird die erkaltete Alkohollösung mit ungefähr dem gleichen Volumen Wasser vermischt, so wird das Jodür als citrongelber Niederschlag gefällt. Aber nach einigen Minuten sieht man in der Flüssigkeit eine Bewegung der Theilchen entstehen, und bald darauf ist der ganze Niederschlag in schimmernde Krystallblältchen von zinnoberrother Farbe verwandelt. Offenbar also hat dieser Körper, gleich dem Quecksilberjodür, zweierlei Zustände, einen gelben und einen rothen, verbunden wahrscheinlich, wie bei jenem, mit einer Dimorphie. Leider gelang es bis jetzt nicht, dasselbe in der gelben Form zu fixiren und krystallisirt zu erhalten. Beim freiwilligen Verdunsten der Alkohollösung, in der es offenhar in der gelben Form enthalten ist, erhält man rothe Krystalle, und ohne Zersetzung ist es nicht schmelzbar. Schon bui $130^{\circ}$ verwandelt es sich in schwarzes Jodtellur.

-) Freund Haidinger wird ibr optisches Verhalten und ihre Form näher bestimmen.

$\boldsymbol{W}$. 
Eine Cyanverbindung konnte wenigstens nicht durch Auflösen des Tellurmethyloxyds in wässeriger Blausäure hervorgebracht werden. Beim Verdunsten blieb die Base unverändert zurück.

Dagegen scheint es ein Schwefeltellurmethyl zu geben, das wir indessen aus Mangel an Material nicht näher studiren konnten. Leitet man in die Lösung des Tellurmethylchlorürs Schwefelwasserstoffgas, so entsteht ein weifser, flockiger Niederschlag ( $\mathrm{C}^{2} \mathrm{H}^{3} \mathrm{TeS}+\mathrm{C}^{2} \mathrm{H}^{3} \mathrm{TeGl}$ ?), der später gelblich wird, indem die Flüssigkeit einen höchst widerwärtigen Geruch annimmt. Destillirt man nun, so geht mit dem Wasser ein äufserst übelriechender, schwerer, ölförmiger Körper von rothgelber Farbe über, der bei der Oxydation mit Königswasser Schwefelsäure bildet. Sätligt man die Lösung des Tellurmethyloxyds mil Schwefelwasserstoff, so entsteht eine schwache weilsliche Trübung. Destillirt man nun, so scheidet sich, so wie die Wärme einwirkt, weilser Schwefel aus und es geht ein gelbes Oel über, welches nur reducirtes Tellurmethyl zu seyn scheint.

Verbindungen der Acetone mit zweifach-schwefligsauren Alkalien;

von Dr. Limpricht.

Die Entdeckung Bertagnini's, dafs die Aldehyde mit den zweifach-schwefligsauren Alkalien krystallisirbare Verbindungen bilden, gehört gewifs zu den fruchtbarsten, welche in neuerer Zeit gemacht worden sind. Wegen der Unlöslichkeit dieser Verbindungen in einer gesättigten Lösung des zweifach - schwefligsauren Alkalis lassen sie sich sehr gut zur Reindarstellung der Aldehyde benutzen, und käme die Fähig- 